\title{
A CONSTITUIÇÃO DA IDENTIDADE LINGUÍSTICA SURDA: A NARRATIVIZAÇÃO AVALIATIVA SURDA SOBRE LÍNGUA PORTUGUESA E LIBRAS
}

\author{
Marília do Socorro Oliveira Araújo ${ }^{1}$ \\ Elenilce Reis Farias Peixoto ${ }^{2}$ \\ Rosângela do Socorro Nogueira de Sousa ${ }^{3}$
}

\begin{abstract}
RESUMO
Este trabalho é um recorte de pesquisa cuja base teórica abarca a Análise de Discurso Crítica (ADC) e os Estudos Surdos. Objetiva-se, de modo geral, analisar como são avaliados alguns aspectos do mundo (relação com a Língua Portuguesa e a Libras) por uma aluna surda. Especificamente, busca-se identificar como a estudante surda narrativiza sua experiência e, por conseguinte, compreender as implicações dessas avaliações para seu processo de identificação. Metodologicamente, trata-se de uma pesquisa qualitativa, de base etnográfica. $\mathrm{O}$ objeto são respostas obtidas a partir de uma entrevista com uma estudante surda sobre a sua experiência com a Língua Portuguesa. A análise de dados foi conduzida a partir da ADC e da Linguística Sistêmico Funcional (LSF). A função discursiva pontuada aqui é a identificacional, a partir da análise da categoria avaliação. Os resultados apontam para uma construção negativa sobre a Língua Portuguesa e seu ensino e positiva sobre a Libras, constituindo uma identidade que se afasta da perspectiva ouvintista sobre a surdez assim como da relação entre o surdo e o ensino da Língua Portuguesa como sua segunda língua.
\end{abstract}

Palavras-chave: Identidade surda. Discurso. Lingua Portuguesa. Libras.

\section{THE CONSTITUTION OF DEAF LINGUISTIC IDENTITY: THE DEAF EVALUATIVE NARRATIVIZATION ABOUT PORTUGUESE LANGUAGE AND LIBRAS}

\begin{abstract}
This work is an excerpt of research whose theoretical basis encompasses Critical Discourse Analysis (ADC) and Deaf Studies. The objective is, in general, to analyze how some aspects of the world (relationship with the Portuguese language and Libras) are assessed by a deaf student. Specifically, it seeks to identify how the deaf student narrates her experience and, therefore, to understand the implications of these assessments for her identification process. Methodologically, this is a qualitative, ethnographic research. The object is answers obtained from a short interview with a deaf student about her experience with the Portuguese language. The data analysis was conducted from the ADC and Functional Systemic Linguistics (LSF). The discursive function punctuated here is the identification, from the analysis of the evaluation category, seeking to identify how the deaf student narrativizes their experience, constituting their identity. The results point to a negative construction about the Portuguese Language and its teaching and positive about Libras (Brazilian Sign Language), constituting an identity

\footnotetext{
${ }^{1}$ Mestranda do Programa de Pós-Graduação em Cidades, Territórios e Identidades (PPGCITI), da Universidade Federal do Pará (UFPA). Bolsista FAPESPA. E-mail: lilia_olive@ hotmail.com

${ }^{2}$ Mestre em Cidades, Territórios e Identidades (PPGCITI) pela Universidade Federal do Pará. Professora da Universidade Federal Rural da Amazônia. E-mail: nilcefariasreis@gmail.com.

${ }^{3}$ Doutora em Linguística pela Universidade Federal do Ceará. Professora Adjunto I da Universidade Federal do Pará (Campus Universitário de Abaetetuba). Professora do Programa de Pós-graduação PPGCITI (UFPA/Campus de Abaetetuba e da Faculdade de Ciências da Linguagem-FACL E-mail: ronogueiraufpa@gmail.com
} 
that departs from the listener's perspective about deafness as well as the relationship between the deaf and the teaching of Portuguese language as their second language.

Keywords: Deaf Identity. Discourse. Portuguese Language. Libras.

Data de submissão: 25.04 .2021

Data de aprovação: 23.05 .2021

\section{INTRODUÇÃOO}

O presente artigo tem como tema a constituição da identidade linguística surda, a partir da narrativização avaliativa surda sobre Língua Portuguesa e Libras. Objetiva-se analisar como são avaliados alguns aspectos do mundo, neste caso a relação com a Língua Portuguesa e a Libras, por uma aluna surda. Especificamente busca-se identificar como a estudante surda narrativiza sua experiência de ser surda falante de Libras como sua primeira língua e tendo a Língua Portuguesa como sua segunda língua, neste caso ensinada a ela na modalidade escrita no ambiente escolar, e assim, compreender as implicações das avaliações feitas pela aluna para seu processo de identificação. Assim, temos como pergunta de pesquisa: como a aluna surda avalia discursivamente a Língua Portuguesa e a Libras no contexto de sala de aula?

Nosso interesse nessa questão é justificado pela teoria que baseia este estudo, a Análise Crítica do Discurso (ADC), de vertente britânica, tendo como principal representante Norman Fairclough. A ADC, em um sentido amplo, refere-se a um conjunto de abordagens científicas interdisciplinares para estudos críticos da linguagem como prática social, e define-se pela motivação de "investigar criticamente como a desigualdade social é expressa, sinalizada, constituída, legitimada pelo uso do discurso" (WODAK, 2004, p. 225).

Desse modo, partimos da hipótese de que a aluna surda ao narrativizar sua experiência acerca das línguas em questão tem a possibilidade de afirmar discursivamente sua identidade linguística e desmistificar olhares pejorativos atribuídos à Libras e a surdez. Essa condição é representada discursivamente e a perspectiva da linguagem como parte irredutível da vida social pressupõe relação interna e dialética entre linguagem e sociedade, uma vez que questões sociais são, pelo menos parcialmente, também questões discursivas e vice-versa. Assim, além de ser um modo de representar o mundo e de interagir nele, a linguagem como discurso também é um modo de identificar a si mesmo/a e a outrem.

A Língua Portuguesa e a Libras são as línguas que transitam o cotidiano das pessoas surdas no Brasil. A educação de surdos está respaldada pela Lei 10.436/2002, pelo Decreto 5.626/2005 e pela Lei 13.005/2014, o qual estabelece o Plano Nacional de Educação para o período de 2014-2024. Essa legislação apoia a educação bilíngue, ou seja, reconhece que as duas línguas em questão devem estar presentes na formação do aluno surdo, sendo uma língua de instrução (língua usada na interação) e língua de ensino (língua que faz parte do currículo para ser ensinada). A Libras é reconhecida como primeira língua das pessoas surdas e a Língua Portuguesa como segunda, na sua modalidade escrita. $\mathrm{O}$ bilinguismo constitui um ponto de partida para uma discussão política sobre as questões de identidades surdas, relações de poder e conhecimento entre surdos e ouvintes (QUADROS, 2019). É neste campo de discussão que situamos esta pesquisa, pois a realidade da educação de surdos comporta ainda muitas barreiras, preconceitos históricos que dificultam a convivência pacífica entre surdos e ouvintes no que diz respeito ao processo comunicacional. Este estudo conta ainda com os estudos de Perlin (2013) e Strobel (2009), ambas escritoras surdas que discutem acerca da identidade surda e as lutas da comunidade para a garantia do que consideram como seus direitos.

O conceito de narrativização utilizado neste trabalho advém de Thompson (2011), o qual concebe a narrativização como uma estratégia de operação da ideologia. Esse conceito pontua que as "exigências [da legitimação] estão inseridas em histórias que contam o passado 
e tratam o presente como parte de uma tradição eterna e aceitável" (THOMPSON, 2011, p. 83). Nesse sentido, diante da ação de narrativizar experiências sobre determinados aspectos do mundo, possíveis relações de dominação podem ser sustentadas. Outrossim, a narrativização pode servir como superação dessas relações de dominação. Nesse contexto, a operacionalização desse conceito subsidia a discussão acerca de como uma aluna surda se posiciona quando se expressa acerca da Libras e da Língua Portuguesa em seu contexto de vivência.

No que diz respeito ao termo identificação, nos apoiamos principalmente em Fairclough (2003) que utiliza o termo identificação para destacar o processo contínuo em que as pessoas se identificam e são identificadas. A identificação refere-se ao processo de construção das identidades, um processo nunca completo, nunca fechado, e sim, fluido e dinâmico (HALL, 2014).

O caminho metodológico percorrido foi a partir da abordagem qualitativa. A metodologia de coleta de dados se deu a partir da etnografia, cuja realização ocorreu em uma escola de ensino regular, localizada no município de Abaetetuba, no estado do Pará. Apresentamos uma transcrição, em glosa ${ }^{4}$, de um texto proferido por uma aluna surda. A análise de dados se deu a partir da categoria Avaliação e descrição léxico-gramatical da Linguística Sistêmico Funcional (LSF). Trata-se de um estudo piloto que abarca um projeto maior acerca das identidades surdas. No caso desta pesquisa, a função discursiva a qual nos deteremos é identificacional e volta-se para a formação de identidade pessoal, particular e transformadora.

A afirmação identitária é essencial para apoiar as lutas de grupos que, inseridos em um contexto de desigualdade, sofrem com a exclusão em diferentes aspectos. As pessoas surdas possuem identidade cultural e linguística específica e essa especificidade é conflituosa no convívio social, pois a sociedade está estruturada de modo que não os contempla com condições iguais de acesso e oportunidades. Assim, a luta da comunidade surda pelo reconhecimento e apoio de sua identidade linguístico cultural é progressiva.

\section{PESSOAS SURDAS: UMA MINORIA LINGUÍSTICA}

A relação de poder existente entre povos sempre foi marca profunda no processo de construção de uma identidade própria, devido a dominância de um impor ao outro sua identidade e cultura. Desde tempos remotos, povos são subjugados e forçados a adquirirem uma cultura alheia a si. Isso acontece ainda hoje com o povo surdo que há muito tempo vem lutando contra a hegemonia ouvintista que subjuga a capacidade de relação surda, rechaçando-a como se não houvesse espaço para uma identidade própria:

[...] apesar de esmagados pela hegemonia ouvinte que tenta anular a sua forma de comunicação (a língua de sinais), procurando assemelhá-los cultural e linguisticamente aos ouvintes, resistem a essa imposição, reivindicando seus direitos linguísticos e de cidadania. (SILVA, 2006, p. 15-16).

Essa minoria durante muito tempo não foi vista sob um olhar de diferença linguística, mas sim com um olhar de exclusão, o qual tenta abafar a constituição da sua identidade e cultura. Hoje, os surdos lutam "pelo direito de ser surdo" (PERLIN, 2013, p. 51) em meio a uma sociedade ouvinte majoritária. Isso não necessariamente reflete o querer estar no mesmo espaço físico que os ouvintes, pois estar no mesmo espaço não necessariamente garante a

\footnotetext{
${ }^{4}$ McCleary; Viotti e Leite (2010) definem glosa como uma ferramenta necessária para constituir e aproximar visualmente os textos da língua fonte, a Libras, e da língua alvo, o Português, com o intuito de realizar análise e comparação dos enunciados. A glosa se constitui em palavra grafada em maiúsculo, que representa o sinal com sentido equivalente.
} 
inclusão, tendo em vista que a inclusão deve pressupor, no mínimo, a autonomia de interlocução. Sobre o discurso de inclusão:

É importante compreender que esses discursos inclusivos, da maneira como são construídos e difundidos, acabam por reduzir o conceito de diferença, fazendo com que ele seja entendido como mera diversidade ou como simplesmente o oposto de igualdade. (RODRIGUES; BEER, 2016, p. 664).

Dessa maneira, a classificação dos surdos como "deficientes", denominação fortemente negada pela comunidade surda, é a materialização da exclusão dada pela separação entre a normalidade pregada pela cultura ouvintista e a anormalidade baseada no (não) desenvolvimento da língua oral. De toda maneira, os surdos dispõem de uma língua natural, com a qual agem socialmente e apresentam sua percepção de mundo a partir da modalidade viso motora e não oral auditiva. Desse modo, não há neles a falta de, mas a existência de uma língua que lhe é suficiente para virtualizar o mundo. Desta feita, não há motivo, a não ser a discriminação, para que os surdos sejam nomeados como "deficientes". Perlin afirma que:

A violência contra a cultura surda foi marcada através da história. Constatamos, na história, a eliminação vital dos surdos, a proibição do uso de língua de sinais, a ridicularização da língua, a imposição do oralismo, a inclusão dos surdos entre os deficientes, a inclusão dos surdos entre os ouvintes. (PERLIN, 2004, p. 79).

Todas essas ações resultam em "trucidamento da identidade surda" (PERLIN, 2004, p. 79), em função de um modelo de identidade ouvinte que os julga incapazes. Para Perlin, essa subjugação constitui o "surdicídio", pois muitos sofrem por aceitar a menos valia social imposta, que, segundo a autora, "é como uma violência silenciosa que continua agindo" (2004, p. 80). É importante considerar que as diferenças não são um dado, a priori, mas:

[...] se constroem histórica, social e politicamente; não podem caracterizar-se como totalidades fixas, essenciais e inalteráveis; as diferenças são sempre diferenças; não devem ser entendidas como um estado não desejável, impróprio, de algo que cedo ou tarde voltará a normalidade; as diferenças dentro de uma cultura devem ser definidas como diferenças políticas - e não simplesmente como diferenças formais, textuais ou linguísticas[...]. (SKLIAR, 1999, p. 22-23).

A perspectiva ouvintista sobre a surdez se aproxima da perspectiva médica e se afasta da perspectiva antropológica quando designa o estudo do surdo do ponto de vista da deficiência, da clinicalização e da necessidade de normalização. A ideia de ouvinte presume uma noção que identifica a "nós ouvintes" em contraste com "aqueles surdos" (PERLIN, 2013, p. 59), noção que compreende a diferença como desigualdade, colocando como hegemonia que pauta a relação do sujeito surdo com o sujeito ouvinte e a relação daquele com o mundo. Além disso, cabe dizer que o ouvintismo não é ligado ao preconceito e não é o mesmo que oralismo, mas uma perspectiva ideológica dominante.

O ouvintismo deriva de uma proximidade particular que se dá entre ouvintes e surdos, no qual o ouvinte sempre está em posição de superioridade [...] em sua forma oposicional ao surdo, o ouvinte estabelece uma relação de poder, de dominação em graus variados, em que predomina a hegemonia por meio do discurso e do saber. (PERLIN, 2013, p. 59).

Nesse sentido, Quadros (2005) considera problemático o discurso de inclusão, notadamente, segundo o modelo da escola inclusiva brasileira, na medida em que este impõe o bilinguismo. Chamamos a atenção para a exigência do bilinguismo como uma determinação 
restrita ao surdo. Em “O 'Bi' do bilinguismo na educação de surdos” (2005, p. 26), Quadros identifica que ao surdo na escola é prescrita a condição bi-partida, em que a Libras é um meio de ensino da Língua Portuguesa. A "inclusão" da Libras não faz dessa língua o meio de acesso ao conhecimento.

O bilinguismo e o biculturalismo denotam uma exigência da diversidade imposta pela sociedade anfitriã ao surdo, uma definição sujeita ainda a manter cambaleante a comunidade surda. São, assim, uma forma de etnocentrismo: bilinguismo e biculturalismo mascaram normas, pois mantém a diferença cultural surda como se ela fosse incômoda (PERLIN, 2004, p. 56). Esse processo produz uma interferência na constituição do grupo surdo, portanto, da identidade surda e, assim, no desejo do discurso surdo: a vontade de constituir a própria voz e admiti-la no espaço social mais amplo.

Entendemos a cultura surda como diferença, o mundo de experiência surda como, sobretudo, visual e não ouvinte. Os discursos hegemônicos narram a condição de surdo e impõe ao surdo a condição de não ouvinte como marca de afetação. Ao combater a perspectiva ouvintista da condição de ser surdo, é importante considerar o que Skliar defende quando afirma que:

Dar lugar às narrações surdas sobre a surdez constitui, dessa forma, um processo de
desouvintização. O processo de desouvintização mencionado supõe, entre outras
coisas, uma denúncia acerca das práticas colonialistas dos ouvintes sobre os surdos e,
ao mesmo tempo, uma desmistificação das narrativas ouvintes hegemônicas sobre a
língua de sinais, a comunidade e as produções culturais dos surdos (SKLIAR, 1999,
p. 24).

Ao estabelecer esse protagonismo começamos a abrir os espaços de luta por políticas públicas que se encontram regulamentadas na legislação brasileira como discurso de direitos. $\mathrm{Na}$ lei que regulamenta a Libras, de 2002, há o reconhecimento da língua. A emergência dessa lei favoreceu a profissionalização do intérprete e despertou uma proliferação de pesquisas da questão surda nos seus diversos aspectos. A Lei ${ }^{\circ}$. 10.436, em seu artigo $1^{\circ}$ institui:

É reconhecido como meio legal de comunicação e expressão a Língua Brasileira de Sinais - Libras e outros recursos de expressão a ela associados. Parágrafo único Entende-se como Língua Brasileira de Sinais Libras - a forma de comunicação e expressão, em que o sistema linguístico de natureza visual-motora, com estrutura gramatical própria, constituem um sistema linguístico de transmissão de ideias e fatos, oriundos de comunidades de pessoas surdas do Brasil. (BRASIL, 2002).

O reconhecimento legal da Libras como uma língua natural abre o espaço para a discussão da necessidade dessa língua ser inserida como objeto de ensino na escola. No entanto, ainda não presenciamos ações efetivas que retirem a Libras de língua de instrução e a coloque como língua ensinada no sistema escolar brasileiro. Outro documento que cria uma representação institucionalizada sobre a surdez é o Decreto $\mathrm{n}^{\circ} 5.626$, de 22 de dezembro de 2005, Art. $2^{\circ}$, que define a pessoa surda:

Para fins deste Decreto, considera-se pessoa surda aquela que, por ter perda auditiva, compreende e interage com o mundo por meio de experiências visuais, manifestando sua cultura principalmente pelo uso da Língua Brasileira de Sinais - Libras. Parágrafo único. Considera-se deficiência auditiva a perda bilateral, parcial ou total, de quarenta e um decibéis $(\mathrm{dB})$ ou mais, aferida por audiograma nas frequências de $500 \mathrm{~Hz}$, $1.000 \mathrm{~Hz}, 2.000 \mathrm{~Hz}$ e $3.000 \mathrm{~Hz}$. (BRASIL, 2005).

Nessa definição, vê-se a refração do ser surdo e a assunção da surdez a partir da noção ainda de deficiência, denominada deficiência auditiva. Perlin (2013) define a surdez como 
diferença surda, portanto, aborda a surdez na perspectiva da igualdade de direitos, assim admite a forma de resistência surda, como um elemento partícipe na constituição da territorialidade destes sujeitos. Dessa forma, as comunidades surdas mundialmente vêm se organizando sócio politicamente contra essa exclusão que os priva de um convívio social de bem-estar comum.

Nessa perspectiva, atentamos ao campo discursivo como constituinte/parte das práticas sociais capaz de formar olhares acerca da surdez, seja do ponto de vista ouvinte, seja do surdo, pois "questões sociais são, em parte, questões de discurso", e vice-versa (CHOULIARAKI; FAIRCLOUGH, 1999, p. 15). Como exemplo, retomamos de Skliar (1997) as considerações sobre o binarismo latentes no campo da surdez para quem o binarismo atrela ao primeiro termo à adequação à norma cultural e o segundo como existente apenas em oposição à norma e inevitavelmente nela. Esses binarismos:

[...] estão atrelados à produção de uma oposição entre audição e visão: ouvinte/surdo; maioria/minoria; oralismo/bilinguismo; ouvintismo/gestualismo; língua oral/língua de sinais; cultura dos ouvintes/cultura dos surdos; ou, até mesmo, à oposição entre diferença/deficiência. (RODRIGUES; BEER, 2016, p. 666).

Dado que esses binarismos são, a prioristicamente construções discursivas, sua adoção na narrativização da condição da surdez como fato social pode impactar diretamente nas práticas sociais das comunidades surdas e, mais ainda, na relação que se estabelece entre surdos e ouvintes. Em vista disso, consideramos a pertinência de se ancorar em uma perspectiva de estudo que se coloque como ciência engajada, a ADC, que assumimos como aporte teórico metodológico deste trabalho a fim de compreender os discursos da aluna surda como um momento das práticas sociais.

\section{ANÁLISE DE DISCURSO CRÍTICA: UM MODELO TEÓRICO METODOLÓGICO INTERDISCIPLINAR}

Dada a perspectiva de que a ADC é uma abordagem interdisciplinar para estudos críticos da linguagem como prática social, e que se propõe a subsidiar abordagens sociodiscursivas, que buscam desvelar questões de poder e ideologia subjacente ao discurso (RAMALHO; RESENDE, 2016, p. 14), ela se coloca como perspectiva pertinente para tratar dos discursos sobre a surdez a partir da narrativização do surdo.

\footnotetext{
É habitual, definir a comunidade de surdos, como uma minoria linguística. Essa descrição está baseada no fato de que a língua de sinais é utilizada por um grupo restrito de pessoas as quais em uma definição tradicional deveriam viver uma situação de desvantagem social, de desigualdade e participar de uma forma limitada na vida da sociedade majoritária. (SKLIAR, 1999, p. 87).
}

Dada essa condição, a ADC aponta o caminho para a análise porque "teoriza em particular a mediação entre o social e o linguístico" (SILVA, 2010, p. 110). Para a ADC, a linguagem perpassa todos os níveis da vida social: estruturas (fixas), práticas (intermediária) e eventos (flexíveis). Em linhas gerais, segundo Ramalho e Resende (2016, p. 17) constitui a estrutura, o sistema linguístico; a prática social, a ordem do discurso e o evento, o texto. "O conceito de prática social refere-se a uma entidade intermediária, que se situa entre as estruturas sociais mais fixas e as ações individuais mais flexíveis" (RAMALHO; RESENDE, 2016, p. 16). A linguagem, neste caso, é entendida como "prática social e como instrumento de poder" (RAMALHO; RESENDE, 2016, p. 13), manifestando-se nas relações sociais através dos discursos individuais e coletivos.

Embora a ADC apregoe a existência de dois significados de discurso, cabe dizer que discurso, aqui, refere-se a uma maneira mais particular de representar experiências vivenciadas 
no mundo (RAMALHO; RESENDE, 2016, p. 19). Tendo isso em mente, a análise se dará sobre a forma como um sujeito surdo discursiviza sua experiência no/com o mundo.

Ainda sobre a posição do discurso em ADC, esse é determinado pelas estruturas sociais, mas, ao mesmo tempo, tem efeito sobre a sociedade ao reproduzir ou transformar tais estruturas. Assim, o discurso configura-se como a maneira de agir sobre o mundo e as/os outras/os e a maneira de representar a realidade, o que pressupõe a manutenção de relações de poder e modos de operação de ideologias, bem como transforma, constitui relações sociais e identidades (FAIRCLOUGH, 2003).

Segundo Ramalho e Resende (2016), a ADC toma a linguagem como discurso, entendido como um momento, uma parte, de toda prática social, como uma parte irredutível do modo como agimos e interagimos, representamos e identificamos a nós mesmos, aos outros e a aspectos do mundo por meio da linguagem. Os modos (agir, interagir, representar e identificar) como o discurso se figura nas práticas sociais estão correlacionados com os três principais significados do discurso, que são: significado acional, representacional e identificacional. Estes significados estão ligados aos elementos de ordem do discurso que são gêneros, discursos e estilos. Assim, tal como os elementos de ordens do discurso, os significados do discurso exercem uma relação dialética e são internalizados uns pelos outros.

Para realizar a análise de discurso crítica é fundamental compreender a LSF, pois ela é, de acordo Fairclough (2003), uma teoria que é voltada para a compreensão da relação entre a linguagem e outros elementos constituinte da vida social, haja vista que o sistema social representa e relaciona-se com as manifestações linguísticas implícitas e explícitas da prática social. "Ela é voltada para a descrição da linguagem como uso em determinado contexto, pois se entende que é o uso da linguagem que molda o sistema" (SILVA, 2010, p. 112). Ademais, é a LSF que dará base para a descrição linguística e ADC através de categorias analíticas.

A LSF caracteriza-se como teoria semiótica preocupada com todas as manifestações e usos da linguagem, buscando sempre desvendar como, onde, por que e para que o homem usa a língua, assim sua grande preocupação é o significado e não a forma sendo, portanto, uma teoria da comunicação humana, ainda assim, o significado é determinador da forma, pois conforme a necessidade do falante em contextos específicos, as escolhas do uso da forma expressam significado desejado (BARBARA, 2009).

Dessa forma, não se pode considerar o texto isolado do contexto, sua constituição abrange os dois aspectos para a realização de análises pautando-se na metafuncionalidade. Segundo Silva (2010), metafunções são denominadas ideacional, interpessoal e textual. Dentro da LSF, a metafunção ideacional se constitui por uma transitividade que abrange processos, participantes e circunstâncias, sendo processos os elementos lexicais; os participantes são elementos que se associam a processos e as circunstâncias que exprimem modo, tempo etc. Já os processos se dividem em material, relacional e mental, havendo ainda relação com instâncias de experiências, que são ação e eventos, estado e relações abstratas com o mundo real e registros mentais de nossas experiências anteriores ${ }^{5}$.

Os conceitos da LSF foram rearticulados por Fairclough a fim de subsidiar linguisticamente a ADC. Assim, a LSF orientará a ADC na aplicação das categorias analíticas que são provenientes de cada significado do discurso (acional, representacional e identificacional). O significado identificiacional em ADC é um dos significados do discurso (Fairclough, 2003) que estabelece relação dialética com outros significados: acional e representacional. Segundo Ramalho e Resende (2016), o significado acional/relacional do discurso é relativo a modos de (inter)agir discursivamente, a gêneros, os quais estão para além de gêneros textuais, são antes gêneros discursivos "tipos de linguagem ligados a uma atividade social particular" (CHOULIARAKI; FAIRCLOUGH, 1999, p. 63). O Significado

\footnotetext{
${ }^{5}$ Para um estudo mais aprofundado, consultar Halliday (2004); Fuzer e Cabral (2014).
} 
representacional está ligado a maneiras particulares de representar aspectos do mundo. É associado a discursos considerados como "tipo de linguagem usado para construir algum aspecto da realidade de uma perspectiva particular".

Por sua vez, o significado identificacional é relativo à maneira de identificar(-se) e associa-se a estilos. Chouliaraki e Fairclough (1999, p. 63), refere-se a estilo como o "tipo de linguagem usado por uma categoria particular de pessoas e relacionado com sua identidade", corroborando a isso, Ramalho e Resende (2016, p. 52-53), afirma que estilos são maneiras de identificar a si e a outros, o que pressupõe identidades sociais e individuais. Essas identidades são modos de representar o mundo e interagir nele, a linguagem como discurso também é um modo de identificar a si mesmo/a e a outrem.

Esse discurso de identificar a si mesmo e ao outro posiciona-se através de afirmações e negações que ocorrem no campo discursivo e se manifestam nas relações e práticas sociais, pois o tipo de linguagem usado em uma categoria particular de pessoas, "expressa, de alguma forma, como essas pessoas se identificam e como identificam os outros" (RAMALHO; RESENDE, 2016, p. 67).

Segundo Fairclough (2003), a identificação é um processo complexo, devido haver diferença entre aspectos pessoais e sociais, entre identidade social e personalidade. $\mathrm{O}$ autor afirma que "a identidade não pode ser reduzida à identidade social, que parte significa que a identificação não é um processo puramente textual, não somente uma questão de língua." (p. 179). A comunidade surda possui identidade coletiva enquanto grupo de resistência que luta contra a exclusão social, ainda assim, as identidades individuais são várias, pois abrangem a diferença surda. Essas são, ainda, da ordem do gênero, da sexualidade, da classe social; entre o surdo de família ouvinte e o surdo de família surda; entre o "surdo implantado" (uso de aparelho auditivo) e "surdo não-implantado". Portanto, a identidade surda é híbrida. Perlin (2013), classifica as identidades surdas em identidade política, híbrida, flutuante, embaçada, de transição, entre outras.

Para executar uma análise acerca das formas de identificação, a ADC estabelece categorias de análise, entre elas: Avaliação, Coesão, Estrutura Genérica, Identificação Relacional, Intertextualidade etc. Para proceder este estudo, faremos uso da categoria analítica Avaliação. Conforme Ramalho e Resende (2016), essa categoria é moldada por estilos, no que se refere a apreciações ou perspectivas do locutor, mais ou menos explícita, refletindo sobre aspectos do mundo, avaliando em bom ou ruim, desejável ou não e assim sucessivamente. Essas avaliações refletem a relação que o sujeito tem com o mundo do ponto de vista da atribuição de valor, indicando que "o modo como as pessoas se expressam nos textos é uma parte importante da maneira como elas se identificam, ou seja, a estruturação de identidades." (FAIRCLOUGH, 2003).

A categoria avaliação pode ser materializada em quatro (4) traços textuais: declarações com juízo de valor; declarações com modalidades deônticas; declarações com verbos de processos mentais afetivos e pressuposições de valor.

Declarações com juízo de valor são, segundo Fairclough (2003), declarações que exprimem o que se deseja ou não, o que é bom e o que é ruim. Em casos mais óbvios, elas se apresentam sobre forma de processo relacional, onde o atributo (que pode ser um adjetivo ou sintagma nominal, ou até mesmo o verbo) concentra o juízo de valor.

Antes de adentrar na questão dos dados, é importante mencionar que este estudo é de natureza qualitativa. Esse tipo de pesquisa lança mão de diversos materiais empíricos, e em se tratando de pesquisa em ADC, os textos são utilizados como principal material empírico (RAMALHO; RESENDE, 2016, p. 75). Esse estudo faz parte de um projeto maior, vinculado ao nosso grupo de pesquisa, que se debruça diante de estudos de grupos minoritários e seus direitos, à luz da ADC. A comunidade surda, representa então o grupo de minoria linguística ao qual investigamos. Assim, esse projeto maior que deu origem a esse trabalho, investiga os 
processos de escolarização, inclusão e identidades de pessoas surdas em escolas públicas do munícipio.

Para isso, faz-se necessária a articulação entre a ADC e Etnografia. A etnografia tem por objetivo, conforme Geertz (1989, p. 10), “o alargamento do universo do discurso humano". Magalhães, Martins e Resende (2017), pontuam sobre a importância de seguir uma abordagem etnográfico-discursiva para o estudo do discurso. Pontuam também que é de suma importância relacionar o texto ao contexto social e seus participantes para a compreensão textual. Isso implica não perder de vista o papel do discurso na compreensão dos momentos da prática social. Portanto, a ADC e a Etnografia podem assim, segundo Magalhães, Martins e Resende (2017), ser complementárias para a coleta e a análise de dados. Essa relação de complementaridade é articulada para a análise das práticas sociais de que os textos são parte.

O lócus da pesquisa para esse estudo foi uma escola de ensino regular, localizada no município de Abaetetuba, no estado do Pará. Esta escola recebe pessoas surdas para estudarem nas diversas turmas ofertadas regularmente. A pesquisa foi realizada em 2019 com 1 aluna surda do $1^{\circ}$ ano do ensino médio. A participante tem 19 anos, nasceu surda com perda bilateral profunda, utilizou aparelho auditivo em algumas etapas de sua vida e aprendeu Libras como sua língua materna quando era criança, língua que utiliza para sua comunicação e expressão. Após o contato e apresentação da pesquisa, procedeu-se com a assinatura do termo de consentimento livre e esclarecido, o qual foi aderido pela participante antes de iniciar a entrevista.

A entrevista é utilizada aqui como ferramenta de coleta de dados. Após conseguir agendar a entrevista individual, essa ocorreu em uma sala de aula da escola supracitada. Como forma de registro, utilizou-se a gravação de vídeo. A entrevista ocorreu de forma tranquila, foi conduzida totalmente em Libras entre participante e pesquisadora (usuária de Libras) com base em um roteiro de perguntas. Na condução da entrevista, a estudante foi convidada a falar um pouco sobre questões que perpassam a sua escolarização e convivência com as duas línguas. Algumas das perguntas que direcionaram a análise foram: "Você conversa em Libras com colegas e professores no espaço escolar? Explique como é a sua convivência". "Fale um pouco sobre como você aprende os conteúdos de Língua Portuguesa e sobre possíveis dificuldades". "Me fale um pouco sobre sua relação com a Língua Portuguesa, sobre o que você acha dela?"

Após a etapa da entrevista, fizemos a tradução de Libras para a Língua Portuguesa escrita, a fim de compor o corpus. Assim, esse corpus da pesquisa é um texto escrito, exemplo de prática discursiva e faz parte de uma prática social. Ademais, com base no texto gerado a partir da tradução, extraímos algumas glosas, para fins de análise.

O modelo de análise a ser utilizado será o proposto pela Análise de Discurso Crítica. Serão analisadas as categorias de análise textual proposta por Fairclough (2003), de acordo com os significados do discurso (acional, representacional e identificacional). Desse modo, a categoria analítica, Avaliação da ADC, e as descrições léxico-gramaticais da LSF nos darão apoio para a análise de dados enquanto descrição linguística. Para Fairclough (2003), o discurso conforma-se como um dos elementos da prática social, concebido como forma de representação, ação e identificação. Assim sendo, investigar como a aluna surda avalia discursivamente a Língua Portuguesa e a Libras no contexto de sala de aula, se torna imprescindível.

\section{VIVÊNCIAS SURDAS DO ENSINO DE LÍNGUA PORTUGUESA: A AVALIAÇÃO EM PERSPECTIVA SURDA}

Essa seção aborda a análise de dados que se referem às avaliações presentes nas respostas advindas das perguntas sobre a relação da aluna surda com o ensino de Língua Portuguesa. Essas avaliações nos permitem perspectivar a experiência do surdo a partir de sua 
narrativização, tirando do centro a narrativa ouvintista dessa relação. Uma das perguntas dirigidas a aluna foi: "Me fale um pouco sobre sua relação com a Língua Portuguesa, sobre o que você acha dela?". Em sua resposta, a aluna comentou sobre sua vivência em sala de aula, relatando sua rotina. Apresentamos o excerto a ser analisado: (1) "Mais ou menos. Professor oraliza, fala, fala, fala, eu olhar, fácil-não, difícil."

Glosa em Libras

Fácil-não

Tabela 1 - Tradução para a Língua Portuguesa:

\begin{tabular}{ccc}
\hline (Língua Portuguesa) não & É & Fácil \\
\hline Portador & Processo relacional & Atributo \\
\end{tabular}

Fonte: Elaborada pelas autoras

O elemento avaliativo está no atributo "fácil", que, na língua de sinais, como mostra a glosa, é sinalizado "fácil-não", assim é possível identificar o juízo de valor que a aluna atribui à Língua Portuguesa, avaliando-o negativamente.

No mesmo excerto, temos uma outra declaração explícita, com juízo de valor: (2) "Mais ou menos. Professor oraliza, fala, fala, fala, eu olhar, fácil-não, difícil.”

Glosa

\begin{tabular}{|c|}
\hline Difícil \\
\hline Atributo \\
\hline
\end{tabular}

Tabela 2 - Tradução

\begin{tabular}{ccc}
\hline Língua Portuguesa & É & Difícil \\
\hline Portador & Processo relacional & Atributo \\
\hline
\end{tabular}

Fonte: Elaborada pelas autoras

Novamente há um atributo (difícil) explícito que se aplica como um elemento avaliador do portador (Língua Portuguesa), ratificando o juízo de valor atribuído à Língua Portuguesa. Do ponto de vista da aluna surda, a Língua Portuguesa se apresenta como uma realidade intangível e a oralização como algo incômodo e difícil dado que sua experiência com a aula de Língua Portuguesa ocorre como uma violência simbólica a sua primeira língua, a Libras. Como afirma Silva (2016), os discursos são resultados das diferentes perspectivas de mundo que cada um possui, em vista do "lugar" em que se posicionam, ou são posicionadas, em seus contextos sociais. São também resultados das relações sociais que são estabelecidas.

Isso pode ser percebido na avaliação que a aluna faz da Libras, quando a avalia em termos de apreciação estética, indicando o prazer que é poder interagir por meio da Libras. (3) "Ouvinte aprender desejar o que? Libras, muito linda, verdade."

Glosa

LIBRAS, MUITO LINDA


Tabela 3 - Tradução

\begin{tabular}{ccc}
\hline Libras & É & Muito linda \\
\hline Portador & Processo relacional & Atributo \\
\hline
\end{tabular}

Fonte: Elaborada pelas autoras

Aqui, temos uma afirmação feita pela aluna, agora a respeito da Libras. A declaração foi feita em um contexto no qual ela expressava que fica feliz quando há interação e ajuda mútua entre surdos e ouvintes e, desse modo, ouvintes sentem vontade de aprender a língua de sinais. Nessa declaração, o atributo manifesta-se pelo adjetivo linda, fortalecida pelo advérbio muito. Vale ressaltar que, na língua de sinais, são as expressões faciais que tem valor semântico equivalente aos advérbios da língua oral. Constata-se, como afirma Fairclough (2003), que as declarações com juízo de valor referem-se a algo que é desejado ou não, neste caso o desejo é explícito nos sinais utilizados e estão relacionados à importância que se dá à Libras.

Para Fairclough (2003, p. 178), estilos refere-se ao aspecto discursivo das formas de ser, das identidades. Quem somos parte de uma questão de como falamos, como escrevemos, assim como é uma questão de incorporação. O processo de identificação envolve efeitos constitutivos do discurso, ele deve ser visto como um processo dialético no qual discursos são inculcados em identidades.

Logo as avaliações expressas pela aluna são baseadas nas suas percepções como pessoa surda, tomando como parâmetro o modo como se identifica e como identifica determinados aspectos do mundo, como a Libras, sendo possível compreender pelo discurso a afirmação identitária que se desvela, pois as identidades se constituem discursivamente.

Para além das avaliações em termos de dificuldade e estética, outro tipo de avaliação também presente no discurso da estudante se dá a partir de declarações com modalidade deôntica, como mostra a seguir: (4) "Sim, achar. Mas, pessoa olhar, o que? Nome Língua Portuguesa, como? Perguntar-responder. Chama surdo ouvinte, precisar ajuda-mútua, interagir."

De acordo com Ramalho e Resende (2016), as declarações com modalidade deôntica são declarações ligadas a juízo de valor e podem avaliar aspectos do mundo em termos de obrigatoriedade ou necessidade, como algo bom a ser feito. O excerto acima é referente à resposta ao pedido da opinião da estudante sobre a importância ou não da Língua Portuguesa para o convívio social do surdo. A tradução que se faz em Língua Portuguesa escrita, referente à glosa acima é a seguinte: "[...]sim, eu acho. Mas, as pessoas surdas têm dúvidas sobre as palavras em Língua Portuguesa, assim como ouvintes têm dúvidas em relação aos sinais, então se chama um ao outro e se questiona sobre. É preciso que haja ajuda mútua, interação".

Nesse sentido, a aluna avalia que precisa haver trocas, reciprocidade entre surdos e ouvintes, marcando assim sua posição quanto ao aspecto do mundo (neste caso, a Língua Portuguesa na relação social entre surdos e ouvintes) em termos de necessidade, corroborando que o discurso de inclusão, baseado apenas na co-presença, não corresponde aos anseios por espaço de atuação e interação do sujeito surdo.

Sobre a experiência subjetivo-afetiva, pode-se dizer que ela se manifesta, em grande medida, a partir de declarações com verbos de processos mentais afetivos. Esse tipo de declaração envolve processos mentais afetivos ligados a avaliações de caráter pessoal. Envolve eventos psicológicos, indicam sentimentos, percepções, desejos e afeições (FUZER; CABRAL, 2004, p. 54). Nesse tipo de declaração, os participantes são tipicamente humanos ou coletivos humanos que sentem, pensam, percebem, desejam. Por isso, a função léxico-gramatical que desempenham na oração é denominada Experienciador. O complemento do processo que se 
refere ao que é sentido, pensado, percebido ou desejado denomina-se Fenômeno (FUZER; CABRAL, 2004, p. 54-55).

Nós seres humanos, fazemos relações entre traços de nossa experiência, ora por identificação, ora por caracterização. Nesse sentido, a LSF, por meio da análise dos aspectos léxico-gramaticais de enunciados, oferece uma contribuição importante para a compreensão da constituição das identidades, das emoções e características sobre determinado aspecto do mundo. Assim, na análise linguística do corpus, quando a aluna surda expressa a sua experiência com a Língua Portuguesa, nota-se que os processos relacionais são fundamentais para essa compreensão. Esses processos têm contribuição importante para identificar, caracterizar, qualificar pessoas, coisas, bem como situações. Do mesmo modo, também são importantes para atribuir pertencimento a determinados grupos sociais e posse. A observação desse tipo de processo pode auxiliar na compreensão da constituição de identidades. E os processos mentais contribuem para veicular emoções, pensamentos e desejos diante da experiência com a Língua Portuguesa e a Libras.

O excerto abaixo é parte da fala da entrevistada e nele encontramos a ocorrência da declaração com verbos de processos mentais afetivos. Vale ressaltar que a aluna surda já teve contato com os sons ambientes através do uso de aparelho auditivo. (5) "Eu surda, não-gostar ouvir, barulho, parar, não-ouvir, calma, bom, paz sentir.”

Tabela 4 - Tradução

\begin{tabular}{ccc}
\hline Eu surda & Não gostar & Ouvir, barulho \\
\hline Experienciador & Processo mental & Fenômeno \\
\hline
\end{tabular}

Fonte: Elaborada pelas autoras

A tradução da glosa corresponde a: "eu não gosto de ouvir barulho". Ela expressa uma avaliação de caráter pessoal e que diz respeito ao fenômeno "barulho", "ouvir", que são avaliados negativamente. Deste modo, é possível compreender que o ato de "parar" corresponde a retirada do aparelho auditivo, situação que permite à aluna sentir-se calma. Esse tipo de avaliação deixa entrever que a surdez não é representada como um problema para o surdo, mostrando que a construção da surdez como um "defeito", "a falta de" é uma construção sóciohistórica e cultural baseada apenas na cultura ouvintista, que estabelece, a partir da sua hegemonia, parâmetros de normalidade que ferem o conceito de diferença que subjaz a formação social coletiva.

Dar condições para que o surdo narrativize sua condição de ser/estar no mundo como surdo permite entrever na linguagem aspectos da cultura surda que, discursivamente, opõem-se a perspectiva ouvintista da surdez como deficiência ou falta de algum sentindo, que o torna estranho ou problemático. Na perspectiva da aluna surda, o binarismo (surdo x ouvinte-normal $\mathrm{x}$ anormal) perde o sentido e a hegemonia, de modo que o surdo não passa a existir a partir do ouvinte, mas sim na possibilidade de convivência em cooperação, na construção da interação entre esses dois sujeitos sociais.

As declarações feitas pela aluna surda sobre a sua relação com a Língua Portuguesa, a aula de Língua Portuguesa e a convivência com sujeitos ouvintes estão relacionadas com a sua identidade surda, que, de alguma forma, expressa positivamente ou negativamente avaliações acerca de sua experiência sobre algum aspecto do mundo, neste caso, a sua experiência com a Língua Portuguesa, tendo como parâmetro a língua de sinais que constitui sua identidade linguística, pois a Libras se constitui como artefato cultural de afirmação identitária da comunidade surda. 


\section{CONSIDERAÇÕES FINAIS}

A discussão que propomos neste trabalho serviu para mostrar como discursos são inculcados em identidades na medida em que são avaliados aspectos do mundo, pois avaliá-los permite desvelar identidades discursivamente constituídas. A análise dos dados demonstrou que há construção negativa sobre a Língua Portuguesa e seu ensino e positiva sobre a Libras, baseada na experiência da aluna surda em questão. Nesse contexto, a identidade que se desvela se constitui a partir do reconhecimento de que a Libras é o artefato principal que caracteriza a identidade cultural surda, por meio de uma afirmação linguística baseada na experiência visual da aluna. Portanto, se afasta da perspectiva ouvintista sobre a surdez e da relação entre o surdo e o ensino da Língua Portuguesa como sua segunda língua.

O processo de escolarização das pessoas surdas, no que se refere ao ensino da Língua Portuguesa como segunda língua, necessita contemplar a identidade cultural do aluno surdo, de modo a garantir o direito linguístico no espaço escolar, pois a Libras é sua língua de instrução. A discussão mostrou como é importante a afirmação linguística identitária da pessoa surda para assegurar melhores condições de acessibilidade na educação e demais aspectos da vida social.

\section{REFERÊNCIAS}

BARBARA, Leila; MACÊDO, Célia Maria Macêdo de. Linguística Sistêmico Funcional para a Análise de Discurso: um Panorama Introdutório. Cadernos de Linguagem e Sociedade, v. 10, p. 89-107. 2009.

BRASIL. Lei ${ }^{\circ}$ 10.436, de 24 de abril de 2002. Dispõe sobre a Língua Brasileira de Sinais Libras e dá outras providências. Diário Oficial da União. Disponível em:

http://www.planalto.gov.br/cCivil_03/LEIS/2002/L10436.htm. Acesso em: 26 jan. 2020.

BRASIL. Decreto $\mathrm{n}^{\circ} 5.626$, de 22 de dezembro de 2005. Regulamenta a Lei $\mathrm{n}^{\circ} 10.436$, de 24 de abril de 2002, que dispõe sobre a Língua Brasileira de Sinais - Libras, e o art. 18 da Lei no 10.098, de 19 de dezembro de 2000. Diário Oficial da União. Disponível em:

http://www.planalto.gov.br/ccivil_03/_Ato2004-2006/2005/Decreto/D5626.htm. Acesso em: 26 jan. 2020.

CHOULIARAKI, Lilie; FAIRCLOUGH, Normam. Discourse in late modernity: rethinking critical discourse analysis. Edimburgo: Edinburgh University Press, 1999.

FAIRCLOUGH, Normam. Analysing discourse: textual analysis for social research. Londres e Nova York: Routledge, 2003.

FAIRCLOGH, Normam. Discurso e mudança social. Coord. Trad. I. Magalhães. Brasília: Editora Universidade de Brasília, 2001.

FUZER, Cristiane; CABRAL, Sara Cristina Scotta. Introdução à Gramática SistêmicoFuncional em Língua Portuguesa. Campinas, SP. Mercado de Letras, 2014.

GEERTZ, Clifford. A interpretação das culturas. Rio de Janeiro: Guanabara; Koogan, 1989.

HALL, Stuart. Quem precisa de identidade? In: SILVA, T. T. (Org.). Identidade e diferença: a perspectiva dos Estudos Culturais. Petrópolis, RJ: Vozes, p. 103-133. 2014. 
HALLIDAY, Michael Alexander Kirkwood. An introduction to functional grammar. 3 ed. Revisada por C. M. I. M Matthiessen. Oxford, Londres: Edward Arnold, 2004.

MAGALHÃES, Isabel; MARTINS, André Ricardo; RESENDE, Viviane de Melo. Análise de discurso crítica: um método de pesquisa qualitativa. Brasília: Editora universidade de Brasília, 2017.

MCCLEARY, Leland; VIOTTI, Evani de Carvalho; LEITE, Tarcísio de Arantes. Descrição de línguas sinalizadas: a questão da transcrição dos dados. Alfa: Revista de Linguística (UNESP. São José do Rio Preto. Impresso). v. 54. p. 265-289, 2010.

PERLIN, Gladis Teresinha Taschetto. O lugar da cultura surda. In: THOMA, Adriana da Silva; LOPES, Maura C. A invenção da surdez. Santa Cruz do Sul: EDUNISC, 2004.

PERLIN, Gladis Teresinha Taschetto. Identidades surdas. In: SKLIAR, Carlos (Org.). A surdez, Um olhar sobre as diferenças. Editora Mediação: Porto Alegre, 2013.

QUADROS, Ronice Muller de. O bi do bilingüismo na educação de surdos In: Surdez e bilingüismo.1 ed. Porto Alegre: Editora Mediação, 2005, v.1, p. 26-36

QUADROS, Ronice Muller de. Libras. 1 ed. São Paulo: Parábola, 2019.

RAMALHO, Viviane; RESENDE, Viviane de Melo. Análise de discurso (para a) crítica: o texto como material de pesquisa. Campinas, SP. Pontes Editores, 2016.

RODRIGUES, Carlos Henrique; BEER, Hanna. Direitos, políticas e línguas: divergências e convergências na/da educação de surdos. Educação \& Realidade, Porto Alegre, v. 41, n. 3, p. 661-680, jul./set. 2016.

SILVA, Luzia Rodrigues da. Representação e Identidades: um estudo crítico do discurso. In: RESENDE, Viviane de Melo; PEREIRA, Fábio Henrique. (Orgs.). Práticas Socioculturais e Discurso: Debates Transdisciplinares. Covilhã: LabCom books, 2010.

SILVA, Vilmar. Educação de surdos: uma releitura da primeira escola pública para surdos em Paris e do congresso de Milão em 1880. In: QUADROS, Ronice Muller de (org.). Estudos surdos I. Petrópolis: Arara Azul, 2006.

SKLIAR, Carlos. A Invenção e a Exclusão da Alteridade "Deficiente" a Partir dos Significados da Normalidade. Educação \& Realidade, Porto Alegre, v. 24, n. 1, p. 15-32, 1999.

SKLIAR, Carlos. A Educação para os Surdos entre a Pedagogia Especial e as Políticas para as Diferenças. In: Seminário Desafios e Possibilidades na Educação Bilíngue para Surdos, 2 , 1997, Rio de Janeiro. Anais. Rio de Janeiro: INES, 1997. p. 32-47. Disponível em: http://www.dominiopublico.gov.br/download/texto/me002964.pdf.Acesso em: 15 fev. 2020.

STROBEL, Karin. As imagens do outro sobre a cultura surda. 2 ed. rev. Florianopolis: ed. da UFSC, 2009. 
THOMPSON, John Brookshire. Ideologia e cultura moderna: teoria social crítica na era dos meios de comunicação de massa. 9 ed. Petrópolis, RJ: Vozes, 2011.

WODAK, Ruth. Do que trata a ACD - um resumo de sua história, conceitos importantes e seus desenvolvimentos. Linguagem em (Dis)curso. CALDAS-COULTHARD, C. R. \& Figueiredo, D. de C. (Orgs.). Análise Crítica do Discurso, v. 4, n. especial, p. 223-243. 2004. 